\title{
Revisión del Surrealismo para una Educación Artística de lo insólito: del simulacro a la imagen-objeto
}

\author{
Review of Surrealism for an Art Education of the unwonted: from \\ sham to visual conceit
}

\section{Javier Domínguez Muñino}

Universidad de León, España.

javierdzm@gmail.com
Recibido 31/10/2019 Revisado 28/11/2019

Aceptado 11/12/2019 Publicado 31/01/2020

\section{Resumen:}

Proponemos una revisión del Surrealismo desde una perspectiva curricular postmoderna, con metodologías multimodales como la DBAE o la $\mathrm{A} / \mathrm{r} /$ tografía que permitan integrar creatividad e investigación en la Educación Artística. En este sentido, la Vanguardia moderna es recuperada para hacer de ella una relectura que se adapte a las necesidades del área y aproveche el potencial creativo-crítico de los estudiantes. Comprendemos que en este terreno se dan las condiciones favorables para evitar las inercias, y prejuicios más frecuentes, sobre el fenómeno estético: el de un nuevo espacio (surrealista) dominado por el concepto de 'juego' entre textos e imágenes autorreferenciales que invitan a la indagación. Lo que viene acoplándose óptimamente a la dinámica de 'Proyecto' creativo.

\section{Sugerencias para citar este artículo}

Domínguez Muñino, Javier (2020). Revisión del Surrealismo para una Educación Artística de lo insólito: del simulacro a la imagen-objeto. Tercio Creciente, 17, págs. 33-45.

https://dx.doi.org/10.17561/rtc.n17.3

DOMÍNGUEZ MUÑINO, JAVIER. Revisión del Surrealismo para una Educación Artística de lo insólito: del simulacro a la imagen-objeto. Tercio Creciente, enero 2020 . $\mathrm{n}^{\circ} 17$, pp. 33 45. https://dx.doi.org/10.17561/rtc.n17.3 


\begin{abstract}
:
We propose a review of Surrealism from a postmodern curricular perspective, with multimodal methodologies as ABR or A/r/tography which that they will allow the integration of creativity and research in Art Education. In this sense, the modern Vanguard is recovered to make it a rereading that adapts to the needs of the discipline and will take advantage of the creative-critical potential of students. We understand that favourable conditions exist in this area to avoid inertia and more frequent prejudices about the aesthetic phenomenon: the area of a new (surreal) space dominated by the concept of 'riddle' between texts and self-referential images inviting to the inquiry. What is optimally matched to the dynamic of creative 'Project'.
\end{abstract}

\title{
Palabras Clave/Key words
}

Educación Visual; Vanguardias; Surrealismo; Imagen-objeto; Autorreferencialidad; Juego; Digresión

Visual Education; Avant-garde; Surrealism; Visual conceit; Self-referentialness; Ridlle; Digression

\section{Sugerencias para citar este artículo}

Domínguez Muñino, Javier (2020). Revisión del Surrealismo para una Educación Artística de lo insólito: del simulacro a la imagen-objeto. Tercio Creciente, 17, págs. 33-45.

https://dx.doi.org/10.17561/rtc.n17.3

DOMÍNGUEZ MUÑINO, JAVIER. Revisión del Surrealismo para una Educación Artística de lo insólito: del simulacro a la imagen-objeto. Tercio Creciente, enero 2020. n 17, pp. 33 45. https://dx.doi.org/10.17561/rtc.n17.3 


\section{Introducción: ¿por qué el Surrealismo?}

Volver al Surrealismo es, en el campo de la Educación Artística, rehacer un camino que no por muy documentado extingue su potencial. Revisarlo no es sólo la recuperación de una vanguardia histórica, y reafirmar los presupuestos de aquel giro del pensamiento y la creatividad, sino el ejercicio de plantear un paradigma y una casuística que nos servirán para una pedagogía del arte.

El paradigma, es aquél que niega las artes visuales como mero simulacro o espacio de representación teatral (Fried, 2004), afirmando su rotundo papel como hontanar de ideas y provocación de conceptos o relaciones aún por venir. La casuística es aquella producción plástica y visual que irrumpió en torno a esta Vanguardia; reconceptualizando las funciones del arte, y subvirtiendo el rol pasivo o espectador al que habíamos quedado relegados en la concepción tradicional (que no, por tradicional, ha cesado de contagiar las ideas previas y prejuicios de estudiantes 'frente a' los objetos y fenómenos estéticos, como bien podemos comprobar en la práctica docente).

'Repensar' el Surrealismo no es aquí, por tanto, una ambición historicista o adhesión teórico-estética; se trata de asumir lo ya aprendido de aquellos enfoques que alteraron la fenomenología del arte (el cómo 'hacerlo', el cómo 'percibirlo' o 'leerlo' -si cabe-), y de utilizarlo en la docencia de nuestro ámbito como un modelo o paradigma que implica lo epistemológico, lo estético y lo crítico-discursivo. De este modo, al estudiante se le plantea cuestionar: "qué es y cómo conocer"; "qué es y cómo identificar o percibir"; y "cómo operan el pensamiento y la imaginación creativa" (fomentando un flujo dinámico que requiere una metodología multimodal).

Advertimos estos apuntes iniciales acerca del Surrealismo, en tanto somos también conscientes de su distancia y diferencias respecto del momento y posición en que lo observamos. En esta revisión, o replanteamiento, aprovechamos aquellos aspectos útiles para un diseño curricular -o para una línea pedagógica en que inscribir estos diseños conforme a metodologías fundamentadas-; de manera que no tratamos de hacer una traslación literal, o asunción total, de aquellas ideas y contextos que fraguaron ésta, u otras vanguardias en la $1^{\mathrm{a}}$ mitad del $\mathrm{XX}$.

Abunda la literatura que nos ha dado cuenta y testimonio de ello: tanto las fuentes primarias -manifiestos y textos de los propios artistas- (Breton [1924; 1930; 1941; 1953]; Aragon, [1930]; Crevel, [1932]; Magritte, [1946]) como los estudios exegéticos. Lo que sí merece traer a comentario es, en síntesis, el carácter analítico y cientificista que predominó en aquellas corrientes; dominadas, así, por ánimos elitistas y actitudes paracientíficas que se veían desafiados por un fuerte positivismo que marcaba la época. Lo que no impide que hubiera posiciones, por el contrario, metafísicas o espiritualistas 
como la que protagonizó W. Kandinsky o P. Klee (a quienes debemos sus reflexiones y esbozos pedagógicos). Pero tanto unos como otros casos, difícilmente podían sustraerse al marco general del momento: el de una Modernidad cuyos rasgos, trasladados al ámbito curricular, se contraponen o difieren de los que hoy, situados en un currículo postmoderno, defendemos (Efland, Freedman y Stuhr, 2003). Frente a los valores desprendidos entonces (exclusivismo, innovación, progreso unidireccional), hoy nos situamos en otro paradigma axiológico y, por ende, curricular, al que caracterizan las actitudes inclusivas; no sólo por ética o generosidad sino por un profundo cambio de mentalidad que subyace. Sencilla y fundamentalmente hemos venido comprendiendo, desde el pionero Dewey, que la creatividad es una condición inherente a todas las personas; y no el santuario equivalente a cierta y juzgable altura intelectual que, en las vanguardias, entendieron muchos de los artistas. Por no soslayar esta importante cuestión, citemos al caso este claro fragmento, de incuestionable vigencia, del Arte como experiencia:

"Las obras de arte no alejadas de la vida común, ampliamente gozadas por la comunidad, son signos de una vida colectiva unificada. Pero son también una ayuda maravillosa para la creación de esa vida. La reelaboración del material de la experiencia en el acto de expresión no es un acontecimiento aislado confinado al artista y a unas personas que, de vez en cuando, gozan de la obra. En el grado en que el arte ejercita su papel, es también una reelaboración de la experiencia de la comunidad" (Dewey, 1949: 265-266).

El pensador norteamericano, promovedor de que girasen los planteamientos pedagógicos en torno al arte en una de las mayores reformas educativas como bien conocemos, sembró la semilla de un proyecto filosófico que ha excedido al propio autor por varias décadas: lo que hace que a su relectura no reste oportunidad.

Pero estas consideraciones negativas de las vanguardias, no obstante, no quitan que en tan amplio y variado manantial hubiera aspectos de enorme interés: como el de asistir a la figura de artistas que a la par asumen el rol de investigadores, y creadores de un lenguaje y discurso en que el proceso intelectual parecía terminar. Ensayistas posteriores lo han descrito y explicado bien aplicándolo incluso a las artes literarias o a las nuevas formas de escrituras, en que -rasgo esencial de la Modernidad- los artistas no veían completada su labor creativa hasta que también la teorizaban en paralelo o posterior (Friedrich, 1974; Paz, 1989). Precisamente otra virtud que hoy reconocemos al Surrealismo es la de haber desarrollado la intertextualidad: conjugar y permitir el diálogo entre los distintos lenguajes artísticos o de reconocible valor estético, como la escritura y la plástica-visual. Baste recordar piezas como "Carburador infantil" (1919) de Francis Picabia; "El vivo espejo" (1928) y "La traición de las imágenes [Esto no es una pipa]" (1929), ambas de René Magritte; o "Lepidóptera" (1968) de Leonora Carrington, donde leemos 
explícitamente gritos que denuncian situaciones sociales y políticas, así como un poema del inglés John Donne. También se conjugan, si no letras y palabras, signos matemáticos o que funcionan como iconos parlantes y legibles: es el caso de "Las fases de la noche" (1946) de Max Ernst y, volviendo a Magritte, "El temerario durmiente" (1928).

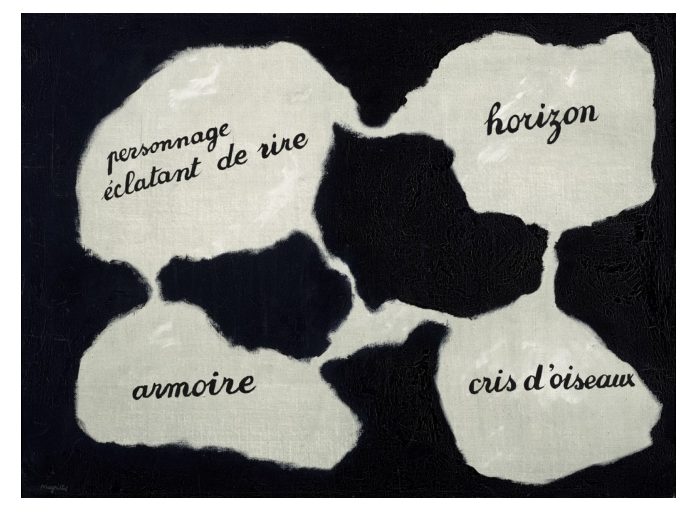

Ilustración 1: El vivo espejo / Óleo, 1928 / René Magritte / Fuente: Web

Allí se concibe y plantea esta posibilidad combinatoria de lenguajes que abre un interesante terreno a las artes visuales, desacotando el estatuto de la imagen que hasta entonces había permanecido vigente. Se trata de una de las más fuertes crisis (en el sentido más positivo) del espacio artístico. Así como habíamos de haber esperado a Courbet y a Toulouse-Lautrec para romper el espacio teatral encuadrado en la imagen, cuando "El origen del mundo" (1866) permite que un cuerpo exceda o desborde el cuadro, y "En el Molino Rojo, el baile" (1890) corta la figura para crear la instantánea capturada de una acción o vida que sigue más allá de esa imagen, hubimos de esperar también a las propuestas surrealistas y dadá para reconcebir la imagen como una cosa propia; como un objeto o idea que goza de soberanía sin desdoblamientos jerarquizados de realidad. Es decir, el replanteamiento de la imagen como un contenido en sí misma en vez de un continente destinado a albergar 'lo representado'. A este giro, justamente, queremos prestar nuestra atención y revisión aprovechándolo en la educación artística. Tomando el pensamiento duchampiano, promovemos la idea central de abandonar la mirada espectadora y pasiva, y empezar a dejarnos alterar por las cosas u objetos artísticos (Duchamp, 2012). En Teatro han venido a llamarlo coloquialmente "romper la cuarta pared" (no ignoremos las aportaciones de Bertolt Brecht a las formas del arte experimental moderno). Aquí, también se trata de romper la ficticia barrera del simulacro-imagen para interactuar, sin jerarquías preestablecidas entre 'el autor' y 'un espectador', acometiendo aquello que los surrealistas preconizaban y defendían como exploración, indagación, 
connatural y necesaria entre participantes o co-jugadores. De ahí que las estéticas derivadas desde entonces hayan otorgado un papel fundamental al concepto de 'juego' en las artes. Adorno apunta en sus Paralipómenos:

"En el concepto de arte, el juego es el momento mediante el cual el arte se eleva inmediatamente por encima de la inmediatez de la praxis y de sus fines. Al mismo tiempo está ligado hacia detrás a la infancia, si no a la animalidad. En el juego, el arte retrocede mediante su renuncia a la racionalidad instrumental por detrás de ésta. La obligación histórica de que el arte alcance la mayoría de edad va en contra de su carácter de juego" (Adorno, 2004: 419).

Citemos también estos reveladores fragmentos, del imprescindible Gadamer, sobre el 'elemento lúdico del arte':

"El espectador es, claramente, algo más que un mero observador que contempla lo que ocurre ante él; en tanto que participa en el juego, es parte de él [...] Uno de los impulsos fundamentales del arte moderno es el deseo de anular la distancia que media entre audiencia, consumidores o público y la obra [...] Es un error creer que la unidad de la obra significa su clausura frente al que se dirige a ella y al que ella alcanza. La identidad hermenéutica de la obra tiene un fundamento mucho más profundo. Incluso lo más efímero e irrepetible, cuando aparece o se lo valora en cuanto experiencia estética, es referido en su mismidad" (Gadamer, 2010: 32-33).

Entre ambas alusiones al juego, radica un elemento llamativo: el de la defensa disruptiva o digresiva en que, lo creativo, se desembaraza de un raciocinio perverso, controlado por algunos, y guiado o predestinado a los papeles y cometidos en cuyo reparto no tenemos participación. De ahí que propongamos alinearnos con una estética 'de lo insólito'; enfocar, la creatividad, hacia las ventajas de 'lo inquietante' y los beneficios inclusivos de una partida sin trucaje, donde las reglas se aprenden performativamente a modo de 'acertijo' (en la acción hermenéutica a la que Gadamer otorgó el papel esencial: pues todos interpretamos porque todos vivimos en relación con las manifestaciones artísticas, y así es como las transmutamos, o confirmamos que 'estaban (y seguirán estando) sin terminar'). Frente a la clausura, la noción de 'lo abierto' permite también que aquellos presupuestos de Dewey no caigan hoy, en el panorama contemporáneo, en barbecho: la coparticipación no es una condición forzada respecto a las artes, sino el comportamiento natural que sólo puede registrar la creatividad. 
Entre el simulacro teatral (una ficción óptica que materializa) y la acción o performatividad (un concepto intangible que subyace), se ubica en el tiempo el arte objetual como género que mejor representa 'lo inquietante' o 'lo insólito'; surgido del programa o planteamiento surrealista, y cuyo más claro extremo es el ready-made duchampiano con ejemplos como el conmovedor "Infeliz" (1919), del propio Marcel tras la pérdida del vínculo familiar con su hermana, o "El enigma de Isidore Ducasse" (1920; 1971) de Man Ray, donde ya habremos de hablar de una intertextualidad con la célebre prosa poética y surrealista de "Los Cantos de Maldoror" (1869) de Lautréamont seudónimo de Ducasse-. Tanto un libro de geometría ajándose al viento sobre el pretil de una ventana, como una máquina de coser (bien recuerda a una máquina de escribir) envuelta en lana atada por una cuerda, son objetos soberanos o imágenes que han roto aquella barrera representacional para encarnar un nuevo y muy distinto estatuto ontológico (modo de ser, aparecer y existir). En este tipo de objeto o "acontecimiento visual" (Mirzoeff, 2003: 34), la interacción sucede, más allá de que sea prestada o tomada, en el propio 'juego' brotado que todo proceso creativo siembra; el de fomentar interrogantes sin las respuestas dictadas, provocando ese acertijo o enigma (como emplea Man Ray en su título) que difícilmente puede, no alterarnos, o dejarnos indiferentes.

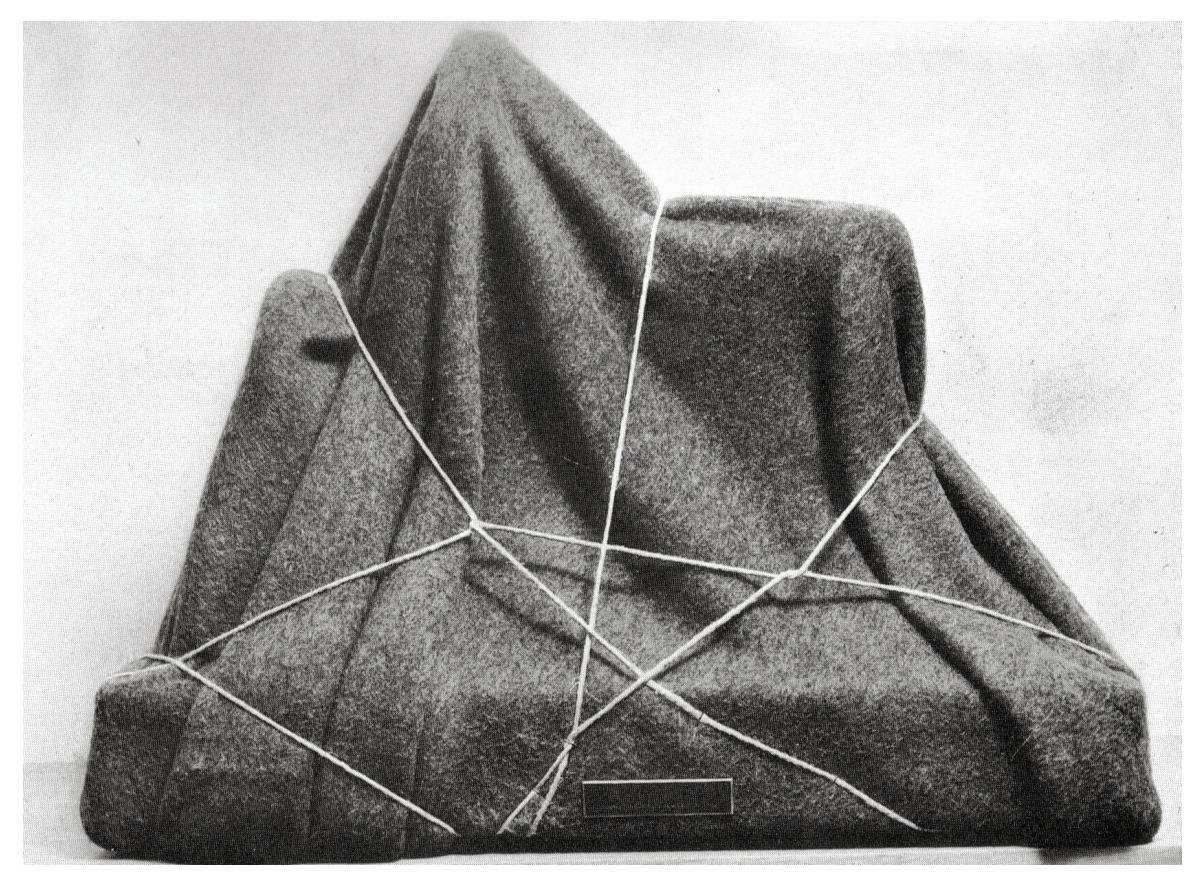

Ilustración 2: El enigma de Isidore Ducasse / Ready-made, 1920; 1971 / Man Ray / Fuente: Web 


\section{Engranaje estético-educativo en torno a un modelo de espacio artístico (más allá del espacio)}

En nuestra área de conocimiento, la Didáctica de la Expresión Plástica y Visual, el alumnado universitario ha demostrado contraer los errores de base que la enseñanza media (inevitablemente incardinada en una sociedad que late allende los diseños curriculares) no ha sabido o podido, en muchos casos, evitar o enmendar. De tal manera, es un fenómeno frecuentísimo que los estudiantes, aun de enseñanza superior, afronten nuestras asignaturas con el estupor y la sospecha a que el ideario les confina. Ese ideario, es sabido, habla de 'función mimética' (mera reproducción), de 'virtuosismo' (habilidades o destrezas), de 'agrado' y 'ornamento' (liquidando así toda dimensión intelectual de las artes), etc. En síntesis, un deformado puzle del que oyó campanas sin conocer el sentido de aquellos sonidos, e inconscientemente lo transmitió. El solo elemento que hemos mencionado en primer lugar (y que constriñe el arte al régimen ocular de la mímesis) deja al estudiante desarmado, y basculando, entre dos frases coloquiales que se contradicen: "yo no sé dibujar" y "eso lo pintaría cualquiera". En cambio, es extraño escuchar que alguien afirme convencido "yo no sé pensar" o "imaginar" o "recordar" o "jugar". De ahí que esta revisión, o recuperación interesada para el campo de la enseñanza artística, nos resulte acuciante y apropiada.

Todo juego se provee de un tablero: ese espacio en que se despliegan sus posibilidades y preguntas, sin la previa delimitación que ha sido refutada. El espacio surrealista (espacio, prevalentemente, conceptual como decimos) dispone oportunidades sobradas para aprovecharlo en el aula. Si tuviéramos que resumir aquí sus rasgos fundamentales, bien podríamos enunciarlos en éstos tres vértices:

-El espacio como un lugar-objeto; por una parte, esto implica que la imagen sustancia ahora una 'inversión significativa de la realidad', y por otro lado esto puede exponerse a los estudiantes como "espacio donde ya no ocurre algo sino que el espacio es lo que ocurre'. De ahí las expresiones lugar-objeto o imagen objetual.

-El espacio disgregado como 'descolocación o descontextualización formal-conceptual', por aquello de la inversión significativa que implica de la realidad (entendida como una afirmación compacta y convencional, sin grietas ni mutaciones). Al disgregarse forma y concepto, se produce esa imagen estética que referíamos de 'lo extraño', 'lo insólito' o 'lo oscilante' (transitando de la tradicional contemplación al juego de la indagación). 


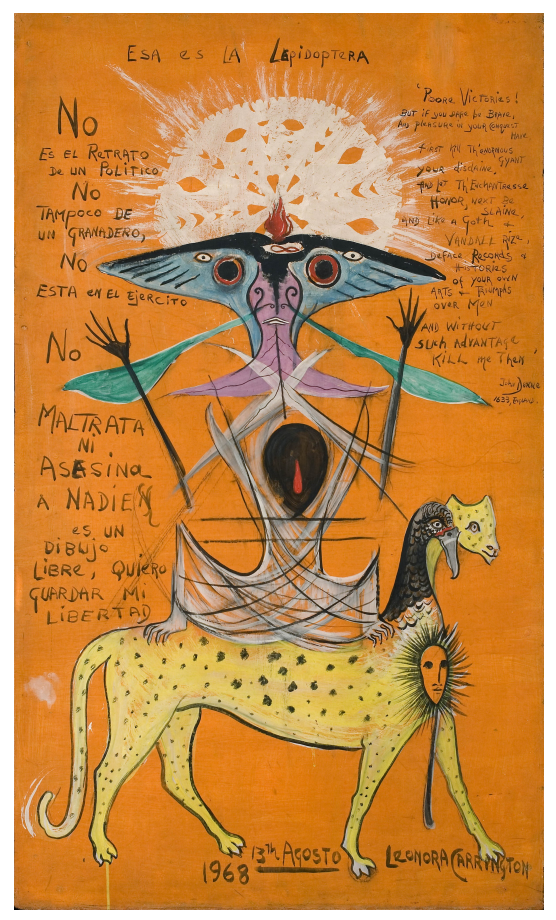

Ilustración 3: Lepidóptera / Técnica mixta, 1968 / Leonora Carrington / Fuente: Web

-Y la quiebra de la lógica en cuanto a la provisión de información visual; un rasgo estrechamente vinculado con la fragmentación de las imágenes artísticas que se manejan en el aula, en tanto estas imágenes surrealistas liquidan o evaporan la 'totalidad unitaria'. Pues los objetos estéticos son liberados del mundo significativo y funcional, quedando abiertos a destinos ignotos a través de reminiscencias, ambigüedades identitarias, metamorfosis o esquemas imaginísticos (recursos, todos ellos, con que dar cobertura al nuevo espacio surrealista).

De esta triangulación que exponemos, se desprende la enorme densidad ontológica de este espacio estético: las imágenes acumulan una amalgama de (im)posibles realidades múltiples, a modo de volatería que dinamiza la imaginación. En esta tormenta o proceso, puede explicarse y poner en práctica también la llamada "escritura automática" (Breton, 2009), que el autor de los tres manifiestos surrealistas (1924, 1930 y 1942) empleara tanto en solitario como en tándems creativos: con los 
poemarios "Los campos magnéticos" (1920) -escrito con Philippe Soupault- y "La Inmaculada Concepción" (c. 1930) -junto con Paul Éluard-. Así, por tanto, reconocemos la importancia de que, en la práctica docente universitaria de Expresión Plástica y Visual, se incorporen tanto los textos como las imágenes (que a su vez destilan imágenes, los primeros, y permiten ser leídas, las segundas).

En el entorno educativo superior, lo más característico del espacio surrealista es el doble juego experimental de codificación y descodificación al que el alumnado se enfrenta; sirviendo, las puestas en común o las dinámicas de grupo, para potenciar y satisfacer estos procesos. Tras la experiencia docente desarrollada en este Área de conocimiento, en las universidades de Sevilla y de León, hemos podido constatar el óptimo funcionamiento de trabajar estos contenidos mediante "Proyectos" (siguiendo el propio modelo que los surrealistas iniciaron).

\section{Una propuesta holística: el Proyecto creativo para el abordaje de los contenidos surrealistas, su discusión y comprensión}

La Educación Artística cuenta con un buen número de modelos pedagógicos y metodologías para afrontar este reto y resolver las problemáticas señaladas aquí muy brevemente. Aunque éste no es el espacio para abrir una discusión metodológica extensa, sí cabe resaltar los métodos en educación artística DBAE y A/r/tografía. La Investigación Basada en Artes, o Disciplina Basada en la Educación Artística (DBAE), nacida de las aportaciones de Elliot Eisner en 1993; y la A/r/tografía, acróstico compilatorio de "art" (arte), "research" (investigación) y "teaching" (enseñanza), fruto de las aportaciones de Rita Irwin y Alex de Cosson en 2003, nos disponen un marco metodológico idóneo para el abordaje de los "Proyectos", caracterizados por la integración (holismo) de medios/lenguajes artísticos.

El propio Eisner se reafirma como precursor en la defensa y fomento de una mirada holística: "[resolviendo] el problema que se origina en la antigua contradicción entre pensamiento abstracto y experiencia sensorial. [Pues] Su propuesta es adoptar una visión artística de los problemas" (Juanola y Masgrau, 2014: 495). En esta misma línea se pronunciaban los propios precursores:

"La investigación basada en artes era -y es- un intento de utilizar las formas de pensamiento y las formas de representación que proporcionan las artes como medio a través de las cuales el mundo puede ser comprendido mejor" (Barone y Eisner, 2012: 11). 
Estos enfoques vienen a celebrar la posibilidad de fructificar, en las aulas, sinergias creativas. Asimismo, distinguimos la aportación de Irwin y de Cosson (situada en 2003) por su origen vinculado estrechamente al ámbito formativo de las artes. Ese contexto germinativo de la $\mathrm{A} / \mathrm{r} /$ tografía también ayuda a entender su holismo como un rasgo más connatural que pretendido. La propia Irwin explica que esta nueva metodología significa:

"indagar en el mundo a través de un proceso continuo de creación artística [...] de forma interconectada [...] para crear nuevos o más amplios significados. [Y añade que] El trabajo a/r/tográfico se realiza, a menudo, a través de los conceptos metodológicos de contigüidad, indagación vital, aperturas, metáfora/metonimia [...] que se representan y se presentan o ejecutan cuando una indagación estética relacional se visualiza como conocimiento encarnado" (Irwin, 2019).

La importancia de emplear metodologías multimodales desde un currículum postmoderno (que superan la brecha dicotómica entre las cuantitativas y cualitativas), y aplicarlas a los contenidos propuestos de la modernidad (los del Surrealismo), permite seleccionar aspectos y hacer relecturas constructivas, de manera que con la mayor versatilidad -y transversalidad- puedan articularse los referidos "Proyectos".

El catedrático en Estética y Teoría de las Artes José Jiménez, cuyo trabajo ha compaginado los intereses antropológicos y educativos sobre el arte, así como especializado en el Surrealismo, nos explica y da testimonio acerca de este modelo o método de hacer en su Teoría del arte:

“[...] el trabajo artístico se llena de implicaciones extraartísticas: sociales, políticas, etc., algo que, a su vez, demandará un ejercicio, ahora ya inmanente, dentro del arte, de reflexión y formulación. Éste y no otro es el auténtico motivo de los textos programáticos, definiciones de 'poética' o de 'estética', y manifiestos, que jalonan la experiencia de las vanguardias. Con la vanguardia, se introduce en el arte la dinámica del proyecto, en la que se expresa una concepción laica, específicamente moderna, de la vida y el proceso histórico [...] En la gran pluralidad de las vanguardias aparece siempre esa constante, en todas ellas se formulan proyectos de arte con los que se pretende cambiar la vida" (Jiménez, 2010: 165).

Con estos esquemas en mente, inquirimos la prevalencia de 'indagar' y 'comprender'; dos acciones sin las cuales sería imposible abordar el verdadero sentido de la propuesta: a saber, una invitación a cada uno y todo estudiante a emprender un viaje sin el listón o destino marcado ('rutas personales') para jugar en la búsqueda y 
resignificaciones. Lo que aspira -humildemente, pero con convicción- a disponer un espacio educativo en artes visuales donde el estudiante pueda comprobarse, a sí mismo, como creador de distintas formas de comprensión de una realidad poliédrica. Son en este territorio, las 'comprensiones', las formas adaptadas que más convenientemente podrán sustituir a las 'conclusiones' tradicionales y cerradas. $Y$ éstas van a depender, fruto del juego creativo, de cada estudiante convertido en co-jugador o participante.

\section{Referencias}

ADORNO, Theodor W. (2004). Teoría Estética (Obra completa, 7). Tiedemann, Rolf (ed.); Navarro Pérez, Jorge (trad.). $1^{a}$ ed., $2^{a}$ imp. Madrid: Akal, 512 p.

BARONE, T.; EISNER, E. W. (2012). Arts Based Research [Investigación Basada en Artes]. $1^{a}$ ed. Thousand Oaks, California: SAGE Publications, 204 p.

BRETON, André (2009). Manifiestos del Surrealismo. Bosch, Andrés (trad.). $2^{\text {a }}$ ed. Madrid: Visor, Colecc. Visor Literario, $279 \mathrm{p}$.

DEWEY, John (1949). El arte como experiencia. Ramos, Samuel (trad. y pról.). $1^{a}$ ed. México: Fondo de Cultura Económica, Colecc. Filosofía, 319 p.

EFLAND, Arthur D.; FREEDMAN, Kerry; STUHR, Patricia (2003). La educación en el arte posmoderno. Vermal, Lucas (trad.). Barcelona: Paidós Ibérica, 237 p.

FRIED, Michael (2004). Arte y objetualidad. Ensayos y reseñas. Guardiola, Rafael (trad.). Madrid: Antonio Machado Libros, Colecc. La Balsa de la Medusa, 364 p.

FRIEDRICH, Hugo (1974). La estructura de la lírica moderna. De Baudelaire hasta nuestros días. Petit, Joan (trad.). $1^{\text {a }}$ ed. Barcelona: Seix Barral, Colecc. Biblioteca breve de bolsillo, Serie Mayor, no 24, 399 p.

GADAMER, Hans-Georg (2010). La actualidad de lo bello. Gómez Ramos, Antonio (trad.); Argullol, Rafael (intr.). $1^{a}$ ed., $7 a$ imp. Barcelona: Paidós Ibérica e I.C.E., Universidad Autónoma de Barcelona, Colecc. Pensamiento Contemporáneo, 124 p.

IRWIN, Rita (2019). A/r/tography. About [Declaración de principios]. Recuperado de: http://artography.edcp.educ.ubc.ca/?page_id=69 (consultado el 13 de octubre de 2019). 
JIMÉNEZ, José (2010). Teoría del arte. $1^{\text {a }}$ ed., 5a imp. Madrid: Tecnos / Alianza, Colecc. Neometrópolis, $281 \mathrm{p}$.

JUANOLA, Roser; MASGRAU, Mariona (2014). "Las aportaciones de E. W. Eisner a la educación: un profesor paradigmático como docente, investigador y generador de políticas culturales". En: Revista Española de Pedagogía, Año LXXII, no 259, pp. 493-508.

MIRZOEFF, Nicholas (2003). Una introducción a la cultura visual. García Segura, Paula (trad.). Barcelona: Paidós Ibérica, 378 p.

PAZ, Octavio (1989). Los hijos del limo. Del romanticismo a la vanguardia. $2^{a}$ ed. Barcelona: Seix Barral, Colecc. Biblioteca de Bolsillo, 241 p. 
Revista de Estudios en Sociedad, Artes y Gestión Cultural

ISSN: 2340-9096

DOI: https://dx.doi.org/10.17561/rtc.n17.3
Número 17

Enero 2020

46

Investigación 